\title{
Shear-Wave Velocity-Based Probabilistic and Deterministic Assessment of Seismic Soil Liquefaction Potential
}

\author{
R. Kayen, M.ASCE ; R. E. S. Moss, M.ASCE ; E. M. Thompson, A.M.ASCE ; R. B. Seed, M.ASCE ; \\ K. O. Cetin, M.ASCE ; A. Der Kiureghian, M.ASCE ; Y. Tanaka ; and K. Tokimatsu, M.ASCE
}

\begin{abstract}
Shear-wave velocity $\left(V_{s}\right)$ offers a means to determine the seismic resistance of soil to liquefaction by a fundamental soil property. This paper presents the results of an 11-year international project to gather new $V_{s}$ site data and develop probabilistic correlations for seismic soil liquefaction occurrence. Toward that objective, shear-wave velocity test sites were identified, and measurements made for 301 new liquefaction field case histories in China, Japan, Taiwan, Greece, and the United States over a decade. The majority of these new case histories reoccupy those previously investigated by penetration testing. These new data are combined with previously published case histories to build a global catalog of 422 case histories of $V_{s}$ liquefaction performance. Bayesian regression and structural reliability methods facilitate a probabilistic treatment of the $V_{s}$ catalog for performance-based engineering applications. Where possible, uncertainties of the variables comprising both the seismic demand and the soil capacity were estimated and included in the analysis, resulting in greatly reduced overall model uncertainty relative to previous studies. The presented data set and probabilistic analysis also help resolve the ancillary issues of adjustment for soil fines content and magnitude scaling factors.
\end{abstract}

\section{Introduction}

Of the several field techniques routinely used to assess triggering of seismic soil liquefaction [standard penetration test (SPT), cone penetration test (CPT), Becker hammer test (BHT), shear-wave velocity $\left(V_{s}\right)$ ], only the shear-wave velocity test measures a fundamental property of the soil. Nevertheless, liquefaction assessment correlations based on in situ penetration index tests are more widely used in engineering practice to estimate the potential for triggering or initiation of seismically-induced soil liquefaction. Compared with $V_{s}$, SPT and CPT penetration methods have the advantage of correlating more directly with relative density, which has a strong effect on the cyclic behavior of saturated soil (Idriss and Boulanger 2008). In contrast, $V_{s}$ is considerably less sensitive to problems of soil compression and reduced penetration resistance when soil fines are present, compared with SPT and CPT penetration methods. Therefore, $V_{s}$ requires only minor corrections for fines content (FC).

The traditional means of estimating $V_{s}$ of soil uses an instrumented borehole, or penetrometer, to measure the travel time of shear waves at various depths. Dual or multiple borehole studies have been used to measure the horizontal and vertical shear-wave velocity properties of the ground. The high cost of performing invasive $V_{s}$ testing stems from drilling cased boreholes, large penetration vehicles, and the instrumentation of the borehole. However, in the last two decades, newly developed noninvasive methods have offered a less expensive alternative. These methods indirectly estimate the soil $V_{s}$ for liquefaction assessment through an inversion of the surface-wave dispersion characteristics of the ground (Stokoe et al. 1994; Andrus et al. 1998; Kayen et al. 2002, 2004a, b).

The objectives of this study are (1) to provide an unbiased as possible assessment of $V_{s}$-based in situ soil liquefaction triggering potential, and (2) to assess the probability of liquefaction triggering for use in performance-based engineering applications. The first objective addresses the problem, noted by Zhou and Chen (2007), of insufficient $V_{s}$ liquefaction field case histories compared with SPT and CPT. Another challenge is related to processing the field case history data. This requires that the uncertainties and distributions associated with the seismic demand and soil resistance variables be quantified and formally evaluated within the model. Bayesian framework and structural reliability methods are used to estimate the probability of liquefaction, which are conditional on $V_{s}$-based capacity and seismic demand. 


\section{Review of $V_{s}$ Liquefaction Relationships}

The development of the cyclic threshold strain approach for assessment of liquefaction potential (Dobry et al. 1982) required identification of the small-strain $V_{s}$ to relate stiffness of the liquefiable layer to threshold acceleration. The field application of this model, relating $V_{s}$ to peak ground acceleration (PGA), using data from the 1981 Westmoreland earthquake for the analysis of liquefaction, was presented by Bierschwale and Stokoe (1984). An early model incorporating a cyclic stress ratio (CSR)- $V_{s}$ triggering resistance curve, proposed by Seed et al. (1983), was developed through SPT$V_{s}$ correlations. In the early 1990s, the growing number of direct field measurements of $V_{s}$ at liquefaction test sites led to several early correlations of effective stress normalized shear-wave velocity $\left(V_{s 1}\right)$ and cyclic stress, (Fig. 1; Robertson et al. 1992; Kayen et al. 1992; Lodge 1994). Andrus and Stokoe (2000) advanced the population of $V_{s}$ data for liquefaction field test sites by adding to these existing data sets measurements from the earthquake events of 1983 Borah

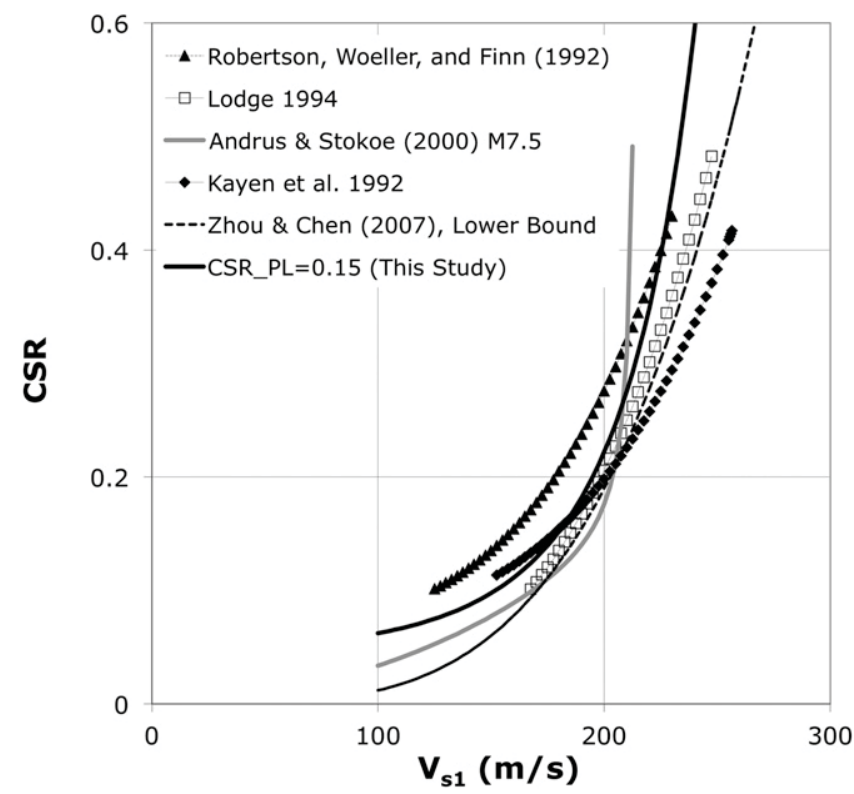

Fig. 1. Comparison of the model from this study, and of prior models, for deterministic shear-wave velocity-based assessment of liquefaction
Peak, Idaho, 1979 Imperial Valley, California, 1981 Westmoreland, California, 1975 Haicheng, China, and the 1964 Niigata, Japan earthquakes, as well as numerous nonliquefaction events recorded at the Lotung LSST Facility in Taiwan. Several new sites from Adapazzari, liquefied during the 1999 Kocaeli, Turkey earthquake, were identified from the study of Bay and Cox (2001) and added to the database. Reliability-based approaches (Juang et al. 2001; Juang et al. 2002) based on the Andrus and Stokoe (2000) data set were developed to characterize the $V_{s 1}$-magnitude-dependent CSR relationship within a probabilistic framework. From the findings of Andrus and Stokoe (2000), it was clear that there was a general paucity of measured $V_{s}$ data in the CSR region above approximately 0.3 , and for $V_{s 1}$, greater than $200 \mathrm{~m} / \mathrm{s}$. By comparison, available SPT and CPT liquefaction resistance correlations were already relatively rich in liquefied and nonliquefied site data in the zone of both highpenetration resistance values and high CSR levels (Cetin 2000; Cetin et al. 2004; Moss 2003; Moss et al. 2005, 2006; Seed et al. 2003; Idriss and Boulanger 2008). From these SPT and CPT studies, the locations of liquefaction sites with both high CSR loading and highpenetration resistance values tended to be clustered in Asia-event data associated with earthquakes in China, Japan, and central Taiwan, where relatively few $V_{s}$ profiles were reported.

To circumvent the lack of field data, Zhou and Chen (2007) described laboratory investigations of the $V_{s}$-based liquefaction resistance of sandy soil and presented their relationships in both best-fit (mean) and lower bound (liquefaction boundary) models. They found that there was no basis for the limiting upper bound normalized velocity $V_{s 1}$ of $215 \mathrm{~m} / \mathrm{s}$ for seismic soil liquefaction based on the laboratory study. They proposed a more conservative procedure than Andrus and Stokoe (2000).

\section{New Field Data}

This study investigates the SPT catalog of Cetin et al. (2000) and CPT catalog of Moss et al. (2003) as the primary sites for new shearwave velocity measurement. The reports catalog locations, data, methods, and investigators of postevent liquefaction field studies, and statistically characterize the critical layer, $a_{\max }, M_{w}$, water table depth, and CSR. The majority of the sites reported in the two studies of Cetin et al. (2000) and Moss et al. (2003) had no corresponding $V_{s}$ profile. The new $V_{s}$ data collected and reported here focus on these well-documented sites in Asia, Greece, and the United States (Fig. 2) and are leveraged and refined using the original postevent

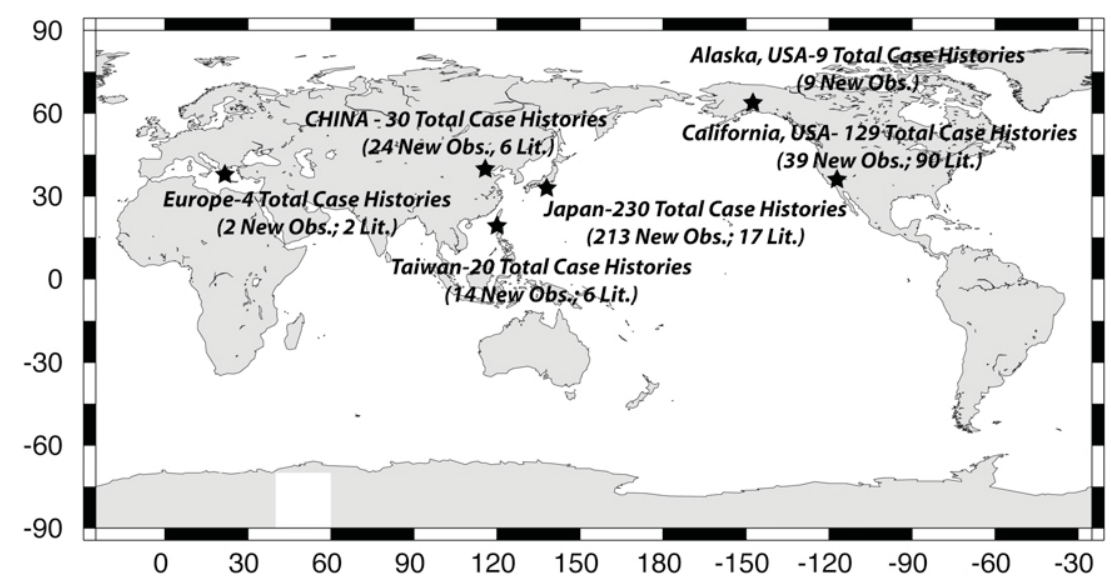

Fig. 2. The 422 shear-wave velocity case histories analyzed for this study were gathered from 301 new case histories derived from 256 new sites collected between 2001 and 2011, as well as 121 case histories from the literature, gathered from 76 sites (background map ㄷ USGS) 
earthquake reconnaissance reports, other soil investigation reports, and local knowledge. The field studies include sites spanning from the disastrous 1948 Fukui City, Japan earthquake to the recent 2011 Great M9.0 Tohoku, Japan earthquake. The $V_{s}$ investigations were performed, when possible, at the exact site previously tested by soil boring, SPT, or CPT. Previous studies indicate that $V_{s}$ can be variable over short distances even within a single geologic unit (Thompson et al. 2007, 2009).

From Cetin et al. (2000), Moss et al. (2003), and additional reports, it was possible to document over 400 penetration test sites with no $V_{s}$ measurements. This study, initiated in 2001, intends to reoccupy all of these sites, where possible. To evaluate these sites efficiently without cumbersome apparatus or the need to negotiate approval for subsurface exploration, this study uses noninvasive surface-wave methods to determine the $V_{s}$ properties of the soil. At most sites, a continuous harmonic-wave spectral analysis of surface waves method (SASW) was used (Kayen et al. 2004a; Fig. 3). SASW are useful for $V_{s}$ profile surveys of liquefaction sites because the characterization needed in the uppermost 15-20 m corresponds with the zone for which the surface-wave test resolution is highest and the required frequency range of the harmonic waves is easy to generate and receive. To estimate the one-dimensional $V_{s}$ structure for hundreds of new sites, the project put an emphasis on efficient workflow for the SASW test and equipment portability.

The SASW test was initially developed at the University of Texas at Austin using active-impulsive sources of either impact hammeror drop-weight type (Nazarian and Stokoe 1984). SASW is a noninvasive linear-array test performed at the earth surface at strain levels in soil in the elastic range of shear strains $<0.001 \%$ (Brown

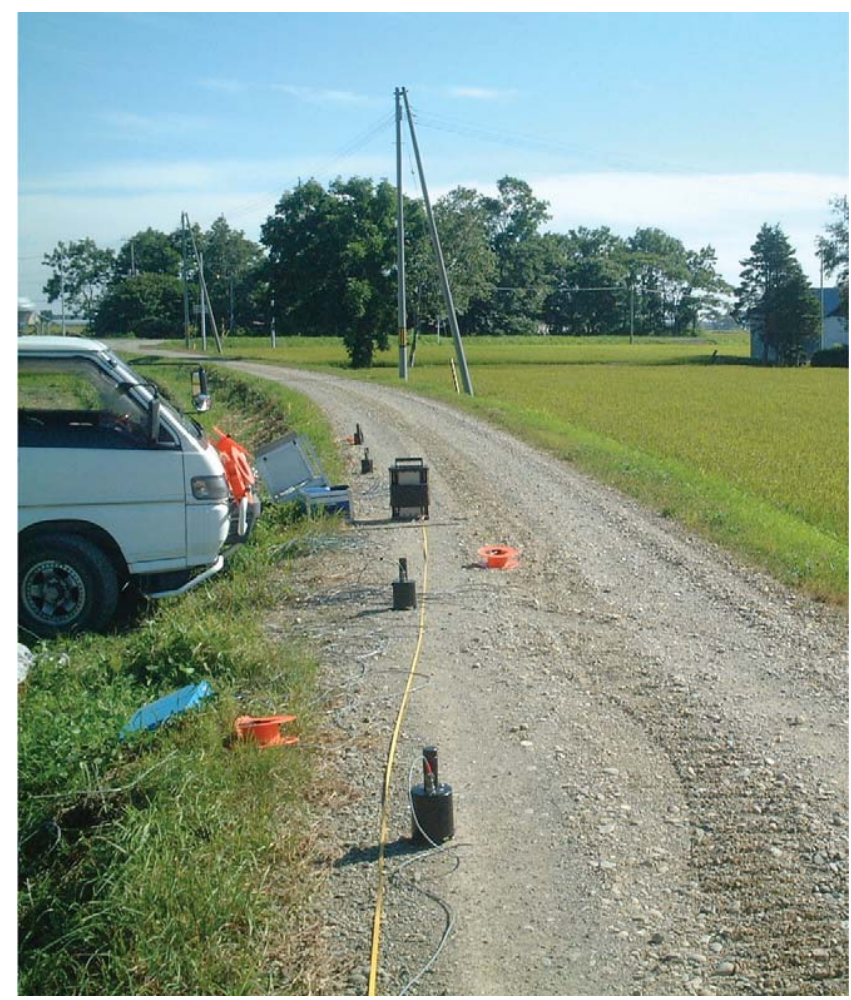

Fig. 3. Typical SASW configuration using the portable frequencycontrolled, 100-kg electromechanical shaker (center unit) with forward and reverse arrays of 1-Hz sensors (Site 41NAGA, Naganuma, Hokkaido liquefied during the Tokachi-oki 1968 earthquake and not liquefied by the Tokachi-oki 2003 earthquake); Photo by Robert Kayen et al. 2002). The frequency-dependent phase differences between pairs of receivers in the array were measured using vertical seismic SS-1 Ranger Kinemetrics sensors and a dynamic signal analyzer, and the dispersion curve was computed based on the phase differences and the receiver spacing. The wavelength range of the dispersion curve was constrained by the source receiver and the inter-receiver distances so that data were selected typically within a phase-difference range of 180 and $720^{\circ}$.

The use of active-impulsive sources allows for a broad range of frequencies to be measured simultaneously, but they are often not repeatable, fail to generate low-frequency vibrations, and are limited in the ability to filter through the source signal only. An activecontinuous harmonic-wave source allows for each frequency to be tested individually, and the signals for that frequency to be passed through a notch filter that dramatically decreases the effect of the external noise while boosting the decibel level of the signal (Rix et al. 2001). The procedures developed in this study used an electromechanical harmonic vibration source identical to that of Rix and Lai (1998) to limit the effects of external noise and increase the accuracy of the dispersion estimates. Inversion procedures for estimating the shear-wave velocity profile at the liquefaction test sites only considered the fundamental mode of propagation, termed a two-dimensional (2D) analysis (Roesset et al. 1991), because these profiles are normally dispersive (soft layers nearest to the surface and phase velocity increasing with wavelength) and not highly heterogeneous. A three-dimensional (3D) effective mode forward analysis would be more appropriate if the profiles were highly heterogeneous and reverse dispersive; that is, not the natural structure of liquefaction soil sites (stiff layer nearest to the surface and phase velocity decreasing with wavelength).

Between 2001 and 2011 (Fig. 2), 206 sites in Asia (resulting in 251 new Asia case histories), 48 sites in the United States (resulting in 48 new U.S. case histories), and 2 sites in Europe (resulting in 2 new European case histories) were visited, profiled, and accepted into the catalog for the $V_{s}$-liquefaction study from a larger set of sites visited for site response and ground deformation analysis. These new $V_{s}$ data represent a quantitative assessment of the majority of liquefaction field observations made throughout the world between 1948 and the present. A listing of the new $V_{s}$ test sites and sites reanalyzed from the literature are presented in Table S1. These new data are merged with the 121 previously reported independent observations from 76 sites by Robertson et al. (1992), Kayen et al. (1992), Mitchell et al. (1994), Lodge (1994), Andrus and Stokoe (2000), and Bay and Cox (2001). The Andrus and Stokoe (2000) data set contains a large number of individual sites that were shaken by between two and six earthquake events. Likewise, this study reports on individual sites that have been shaken numerous times. Thus, the total number of observations in the data set exceeds the number of individual sites.

\section{New Kobe Region, Japan, Data from the M7.5 Hyogo-Nambu Earthquake of 1995}

The region encompassing the greatest quantity of new data collection (86 sites) includes the cities of Kobe, Ashiya, and Nishinomiya, Japan, where extensive damage occurred during the Hyogo-Nambu 1995 earthquake. $V_{s}$ tests were performed at SPT sites that are cataloged in the Kobe-Jibankun Geographic Information System (Tanaka and Okimura 2001) and reported on in numerous postevent investigations (Bardet et al. 1995; Hamada et al. 1995; Shibata et al. 1996; Suzuki et al. 2003). The thickness of the most vulnerable layer and associated FC from penetration test data constrained the critical layer. Strong motion characteristics, strong motion spatial variation, and geological data were reported by Oka et al. (1996), Ejiri et al. (1996), Fujita and Maeda (1984). 


\section{New Japan Region Data from Hokkaido, Tohoku, and Chugoku Regions}

Based on a wealth of Japanese reports and subsurface investigations, a total of 127 new shear-wave velocity sites for the 1948 Fukui earthquake, 1964 Niigata earthquake, 1968 Tokachi-Oki earthquake, 1973 Miyagi-Oki earthquake, 1978 Miyagi-Oki earthquake, 1983 Nihonkai-Chubu earthquake, 1993 Hokkaido-Nansei earthquake, 1993 Kushiro-Oki earthquake, 1994 Kushiro earthquake, 1998 Sanriku earthquake, 2000 Tottori-Seibu earthquake, 2001 Geiyo-Hiroshima earthquake, 2003 Tokachi-Oki earthquake, 2004 Niigata-Chuetsu earthquake, 2007 Niigata-Chuetsu-Oki earthquake, and 2011 Great Tohoku M9 earthquake were collected (Fujimura 2003; Hausler and Sitar 2001; Kokusho et al. 1995; Mori and Kadowaki 2002; Noboru and Eiji 2002; Nozu 2002; Ochiai et al. 2002; Office of the Engineer 1949; Youd et al. 1995).

\section{New China Region Data from the M8 Tangshan Earthquake of 1976}

Chinese liquefaction performance sites were tested in Tangshan City; Fengnan and Luannan Counties, Hebei Province; and Lutai City in Tiensin Province, where sites had been previously explored with SPT or CPT (Wang 1979; Xie 1979; Zhou and Zhang 1979; Zhou and Guo 1979; Arulanandan et al. 1982). At these 24 sites, SASW, the spatial autocorrelation ambient array (SPAC) tests (Kayen et al. 2008b), and Seismic CPT (SCPT) tests (Moss et al. 2008, 2009) were used.

\section{New Taiwan Region Data from the $M_{w} 7.6$ Chi-Chi Earthquake of 1999}

The 1999 Chi-Chi $\left(M_{w}=7.6\right)$ Earthquake triggered liquefaction in native alluvial and fluvial deposits in the cities of Wufeng, Nantou, and Yuan Lin in north-central Taiwan. Based on the reports of the Taiwanese National Center for Research on Earthquake Engineering (NCREE 1999; Liu et al. 2001; PEER 2000; Stewart 2001), 14 new case histories were investigated. The penetration test and soil-boring subsurface characteristics were analyzed by Chu et al. (2004) and Moss et al. (2003). Many of the Taiwan case histories are important because they involve high CSRs between 0.4 and 0.6 , which is a range where previous observations were limited. The Taiwan case histories also involve high FC and marginal plasticity soils.

\section{New Greece Region Data from the $M_{w} 6.5$ Achaia-Elia Earthquake of 2008}

The $M_{w} 6.8$ Achaia-Elia earthquake struck the western Peloponnesian coastal region of Kato-Achaia on June 8, 2008. Two areas separated by $500 \mathrm{~m}$ along the shoreline at Kato Achaia had minor liquefaction in a residential neighborhood adjacent to the Patraikos Gulf (Batilas et al. 2010; Margaris et al. 2010). At one of the two sites, the owner reported that native gravels were excavated from the site and replaced with a loose silty sand fill. Investigators from the University of Patras performed sampling, borehole SPT, CPT, and multichannel analysis of surface waves (MASW) tests at these sites in 2009 and 2010. Both locations were reoccupied to collect SASW data using the controlled harmonic-wave source in 2011. The water table measured at the sites was $0.4 \mathrm{~m}$, and the liquefied zones were well constrained in velocity and depth by the many velocity $\log$ s and borehole lithologies.

\section{New U.S. Region Data from the M6.9 Loma Prieta Earthquake of 1989}

Soil deposits of central San Francisco Bay were exposed to moderate seismic loads during the 1989 Loma Prieta, California earthquake, resulting in localized areas of soil liquefaction damage. SASW testing sites were visited to augment and expand the data set gathered between 1990 and 1992 using CPT, SPT, SASW, and a flatplate dilatometer (DMT), (Mitchell et al. 1994; Kayen et al. 1992, 1998; Seed, R. B., et al. 1990; Chameau et al. 1991). A new suite of SASW sites was investigated along the Pajaro and Salinas River valleys of Santa Cruz and Monterey Counties, Moss Landing and Moss Landing State Beach on Monterey Bay, and at the mouth of the Pajaro River, which was previously tested by SPT and CPT (Bennett and Tinsley 1995; Tinsley and Dupre 1992a, b; Dupré and Tinsley 1998; Boulanger et al. 1995, 1997).

\section{New U.S. Region Data from the M7.9 Denali Fault Earthquake of 2002}

Liquefaction-induced ground failures observed in east-central Alaska from the 2002 Denali Fault earthquake occurred in native fluvial deposits and lake margins along the central range. Liquefaction test sites were identified and mapped during the aerial and ground reconnaissance immediately after the earthquake (Harp et al. 2003; Kayen et al. 2004b). Sand boil ejecta and augered samples on the Slana, Nabesna, Chisana, Tok, Gerstle, and Delta Rivers, at the village of Northway, and Fielding Lake State Park were collected and classified (Kayen et al. 2004b). At these sites (Table $\mathrm{S} 1$ ), the ground for $V_{s}$ was characterized by SASW testing that included transport of the surface-wave equipment by helicopter and backpack.

\section{Shear-Wave Velocity}

The in situ soil $V_{s}$ measurement taken in the field is a small-strain property related to the undisturbed shear modulus $\left(G_{\max }\right)$ of the soil and the soil-mass density $(\rho)$

$$
V_{s}=\left(G_{\max } / \rho\right)^{0.5}
$$

In liquefaction assessments, $V_{s}$ is used as a measure of soil capacity to resist permanent deformations and the rise of elevated porefluid pressures. Field measurements of $V_{s}$ are commonly performed using suspension logging within a borehole, surface source to downhole receiver borehole logging, crosshole logging within boreholes, seismic cone penetrometer, SASW, MASW (Park et al. 1999), and ambient microtremor array methods. Recent comparison of the accuracy and sensitivity of many of these methods include Asten and Boore (2005a, b), Boore and Thompson (2007), and Moss (2007).

The shear-wave velocity of soil is influenced by effective overburden stress, and the void ratio of the soil (Hardin and Drnevich 1972). For a given soil, $V_{s}$ correlates directly with liquefaction resistance through the relationship between void ratio and relative density. It is possible that a soil type of unusual origin will correlate differently given the soil's specific void ratio-relative density relationship. The development of a generalized $V_{s 1}$-liquefaction correlation requires the cautionary understanding that some soils with unusual void ratiorelative density characteristics exhibit liquefaction behavior that differs from the generalized relationships proposed in the past, as well as those proposed in this paper. Typically, the field measurement of $V_{s}$ (as with SPT and CPT) is corrected to a normalized $V_{s 1}$ at the reference stress of 
$100 \mathrm{kPa}$. Liquefiable soils on approximately level ground are assumed to be normally consolidated $\left(K_{o}^{\prime} \sim 0.5\right)$, and by convention (Kayen et al. 1992; Robertson et al. 1992), stress correction $\left(C_{v s}\right)$ is affected by the vertical effective overburden stress $\left(\sigma_{v}^{\prime}\right)$, normalized reference stress $\left(P_{a}\right)$, and the stress exponent 0.25

$$
V_{\mathrm{s} 1}=V_{s} C_{V s}=V_{s}\left(P_{a} / \sigma_{v}^{\prime}\right)^{0.25}
$$

At shallow depths, where the effective overburden stress is small, the writers recommend $C_{V s}$ be capped at 1.5 . The mean and variance of $V_{s 1}$ was calculated directly from the measured data within the critical layer as the average thickness-weighted value of the stepped velocities, typically $2-5$ steps. The uncertainties associated with calculation of the dispersion curve and inversion of individual shear-wave velocity profiles were not addressed in this study. An independent study by Moss (2007) indicates that the average combined coefficient of variation (COV) for the dispersion and inversion calculations of the SASW test data are approximately 0.15 .

In most cases, the critical layer was defined as being the most liquefiable stratum in the profile determined in adjacent SPT and CPT logs using the methods of Cetin et al. (2004) and Moss et al. (2006), respectively. For the test sites, the critical layer used to compute the normalized $V_{s 1}$ is the same as that reported in the two field case history databases for SPT (Cetin et al. 2000) and CPT (Moss et al. 2003) data, and the FC value is taken from their reports.

Data collected for the Denali Fault, Alaska earthquake of 2002 had no adjacent CPT or SPT borehole. Critical layers were based on auger holes adjacent to SASW test sites (Kayen et al. 2004b), where possible. With no penetration log available, the most liquefiable layer was estimated using data from the zone of minimum $V_{s 1}$ in the portion of the stratigraphic logs comprised of Zone A soil [plasticity index (PI) < 12, liquid limit (LL) < 37] (Moss et al. 2006; Seed et al. 2003; Seed, R. B., Cetin, K. O., Moss, R. E. S., Kammerer, A., Wu, J.,
Pestana, J. M., Riemer, M. F., Sancio, R. B., Bray, J. D., Kayen, R. E., and Faris, A., unpublished keynote address, 26th Annual ASCE Los Angeles Geotechnical Spring Seminar, Long Beach, CA, 2003).

\section{Seismic Demand}

CSR is a measure of seismic demand on a soil element and has been represented in the simplified method first proposed by Seed and Idriss $(1971,1982)$ as

$$
\mathrm{CSR}=\frac{\tau_{\mathrm{avg}}}{\sigma_{v}^{\prime}}=0.65 \cdot \frac{a_{\mathrm{max}}}{g} \cdot \frac{\sigma_{v}}{\sigma_{v}^{\prime}} \cdot r_{d}
$$

This study uses Eq. (3) to estimate the seismic demand within the critical stratum for each of the field case histories, where $a_{\max }$ is the peak horizontal ground acceleration at the surface; $g$ is the acceleration of gravity; $\sigma_{\mathrm{v}}$ is the total vertical overburden stress; $\sigma_{v}^{\prime}$ is the effective vertical overburden stress; and $r_{d}$ is the nonlinear shear mass participation factor (Seed et al. 1983, 1984). Liquefaction performance data for $V_{s}$ are gathered from earthquakes with moment magnitude (Kanamori 1977) ranging from 5.5 to 9.2 (Table S1).

In this study, the nonlinear shear-mass participation parameter $r_{d}$ is estimated based on a statistical model of ground response analysis results by Cetin et al. (2004) that showed that $r_{d}$ is nonlinearly dependent upon a suite of factors that include soil depth, average $V_{s}$ of the soil, the amplitude of ground motion, and earthquake magnitude. The $r_{d}$ recommendations of Cetin et al. (2004) characterize the mean and variance and provide an unbiased estimate of $r_{d}$. The results of the analysis were regressed to evaluate the mean $r_{d}$ for a given depth, PGA, and moment magnitude. The variance was estimated from the dispersion of the simulations. The mean $r_{d}$ results can be calculated using Eq. (4) for $d<20 \mathrm{~m}$

$$
r_{d}\left(d, M_{w}, a_{\max }, V_{s, 12 \mathrm{~m}}^{*}\right)=\frac{\left(1+\frac{-23.013-2.949 \cdot a_{\max }+0.999 \cdot M_{w}+0.0525 \cdot V_{s, 12 \mathrm{~m}}^{*}}{16.258+0.201 \cdot e^{0.341 \cdot\left(-d+0.0785 \cdot V_{s, 12}^{*}+7.586\right)}}\right)}{\left(1+\frac{-23.013-2.949 \cdot a_{\max }+0.999 \cdot M_{w}+0.0525 \cdot V_{s, 12 \mathrm{~m}}^{*}}{16.258+0.201 \cdot e^{0.341 \cdot\left(0.0785 \cdot V_{s, 12 \mathrm{~m}}^{*}+7.586\right)}} \pm \sigma_{\varepsilon r d}\right.}
$$

where $d=$ depth in meters, measured at the midpoint of the critical layer (Table $\mathrm{S} 1) ; V_{\mathrm{s}, 12.2 \mathrm{~m}}=$ average $V_{s}$ in the upper $12.2 \mathrm{~m}(40 \mathrm{ft})$ of the soil column; and $a_{\max }=$ PGA in units of gravity. Almost the entire global data set of liquefaction performance sites are at depths shallower than $20 \mathrm{~m}$ (Table S1). The standard deviation for $r_{d}$ for $d<12.2 \mathrm{~m}$ is

$$
\sigma_{\varepsilon r_{d}}(d)=d^{0.850} \cdot 0.0198
$$

and for $d \geq 12.2 \mathrm{~m}$

$$
\sigma_{\varepsilon r_{d}}(d)=12.2^{0.850} \cdot 0.0198
$$

The model parameters for the CSR [Eq. (3)] used in the Bayesian analysis were modeled as the first two terms of a first-order Taylor series expansion about the mean, here presented as Eq. (7) for the means (Moss et al. 2006), and Eq. (8) for the mean-normalized variance $\delta$, and the $\operatorname{COV} \rho$

$$
\begin{gathered}
\mu_{\mathrm{CSR}} \cong 0.65 \cdot \frac{\mu_{a_{\max }}}{g} \cdot \frac{\mu_{\sigma_{v}}}{\mu_{\sigma_{v}}} \cdot \mu_{r_{d}} \\
\delta_{\mathrm{CSR}}{ }^{2} \cong \delta_{a_{\max }}{ }^{2}+\delta_{r_{d}}{ }^{2}+\delta_{\sigma_{v}}{ }^{2}+\delta_{\sigma_{v}^{\prime}}{ }^{2}-2 \cdot \rho_{\sigma_{v} \sigma_{v}^{\prime}} \cdot \delta_{\sigma_{v}} \cdot \delta_{\sigma_{v}^{\prime}}
\end{gathered}
$$

The CSR includes two clearly correlated variables - the total and effective stresses-requiring Eq. (8) to include the COV term $\left(\rho_{\sigma v \sigma v^{\prime}}\right)$. Two other terms that are poorly correlated, $r_{d}$ and $a_{\max }$, are treated as uncorrelated, as well as the other variables that comprise CSR. The COV of $\mu_{a \max }$ is based on the quality of the locally available strong motion data. The COV of the moment magnitude is estimated based on a histogram of values reported in the literature (Moss 2003; Moss et al. 2006). The COV of $r_{d}$ is estimated based on a statistical analysis of ground response results by Cetin et al. (2004). The COV of the total and effective vertical stresses are accounted for as follows: a deterministic estimate is made of the mean unit weight of the soil above and below the water table, whose variance is based 
on statistical studies and is set at $\delta \cong 0.1$ (Kulhawy and Trautmann 1996). The water table mean is taken as the reported estimated depth during the seismic event, and the variance is a fixed standard deviation of $\sigma=0.3 \mathrm{~m}$. The full extent of the critical layer is used to calculate the mean and variance of the stresses. The variance is estimated using a 6- $\sigma$ approach, where the top and bottom depths of the critical layer are assumed to be three standard deviations away from the mean: the $6-\sigma$ range thereby divided by six gives the standard deviation.

\section{Data Quality Assessment}

The case histories were evaluated for seismic demand (CSR) and soil capacity $\left(V_{s 1}\right)$, and then classified according to the quality of the data. Four classes of data, A through D, were used to group the case histories, with D being substandard and excluded from the final case history database. The criteria for the data classes depends on the standard deviation of the CSR value $\left(\delta_{\mathrm{CSR}}\right)$ and the standard deviation of the $V_{s 1}$ value $\left(\delta_{V s 1}\right)$ within the critical layer (Table S1).

Of all the case histories investigated and in the literature from 29 earthquakes and spanning 7 decades, 422 achieved Class $C$ or better and were included in a field case history database (Table S1). The potential ageing of sands after liquefaction during these past decades was not addressed in this study. As such, the velocity values calculated directly from the field experiments were used without adjustments to represent the soil at the time of the earthquake.

\section{Bayesian Analysis}

Bayesian updating provides the probabilistic framework for models that best fit the bounding frontier distinguishing regions of highand low-likelihood of liquefaction occurrence. Curves within this bounding region express a measure of likelihood that initial triggering of liquefaction has, or will, occur. The model for seismic soil liquefaction is formulated as capacity-minus-load typical of a limitstate model for single-component structural reliability problems. The limit-state model for shear-wave velocity $\left(g_{V s 1}\right)$ used in this study is

$$
\begin{aligned}
g_{V s 1}= & \Theta_{1} V_{s 1} \Theta_{2}+\Theta_{3} \ln (\mathrm{CSR})+\Theta_{4} \ln \left(M_{w}\right) \\
& +\Theta_{5} \ln \left(\sigma_{v}^{\prime}\right)+\Theta_{6} \mathrm{FC}+\varepsilon
\end{aligned}
$$

where $V_{s 1}$ is computed using Eq. (2); CSR = earthquake-induced CSR; $M_{w}=$ moment magnitude; $\sigma_{v}^{\prime}=$ effective stress; $\mathrm{FC}=\mathrm{FC}$ where measured from colocated SPT, CPT, or soil boring; $\Theta_{1}-\Theta_{6}$ are model parameter terms estimated through Bayesian updating; and $\varepsilon=$ overall model error term that is treated as a normal random variable with zero mean and unknown standard deviation. The formulation of the limit state model $\left[g_{V s 1}\right.$ in positive-capacity term $\left(V_{s 1}\right)$ and two negative-load terms (CSR, $\left.M_{w}\right)$ ] is solved through an iterative Bayesian updating technique for the best-fit model coefficients $\left(\Theta_{1}, \Theta_{2}, \Theta_{3}\right.$, etc.) that maximize the likelihood function. The contribution of the remaining limit state function terms $\sigma_{v}^{\prime}$ and FC to either capacity or load is determined by Bayesian updating and is reflected in the sign of the model parameters. When the model tips negative, there is some degree of belief that liquefaction failure is likely. The Bayesian updating process used to solve for the $\Theta$ and the standard deviation of $\varepsilon$ is an iterative process to identify the best fit $\Theta$ for each model parameter that results in minimized model error. The region where liquefaction and nonliquefaction data points overlap can be thought of as a mixing zone and is the region likely for finding the threshold of liquefaction triggering.
Each variable in the limit-state function (CSR, $V_{s 1}$, etc.) is assessed for their distribution statistics. The mean and COV are determined for the variables needed to compute CSR and $V_{s 1}$ for each of the sites reported in Table S1. Then, a composite COV for CSR is estimated using a first-order Taylor series expansion about the mean. This allows for the determination of the sample mean and standard deviation for CSR and $V_{s 1}$.

Bayesian updating involves forming a likelihood function, selecting a noninformative prior distribution, calculating a normalizing constant, and then calculating the posterior statistics (Der Kiureghian 1999; Cetin et al. 2000; Moss et al. 2003). Starting with a noninformative prior distribution allows for the computation of an unbiased posterior distribution (Box and Tao 1992). The analysis is performed using the Bayesian updating formula

$$
f(\Theta)=c \cdot L(\Theta) \cdot p(\Theta)
$$

where $\Theta=$ set of model parameters $\Theta_{1}, \Theta_{2}$, etc.; $f(\Theta)=$ posterior distribution; $c=$ normalizing constant; $L(\Theta)=$ likelihood function; and $\mathrm{p}(\Theta)=$ noninformative prior distribution.

The likelihood function for liquefaction triggering is the product of the probabilities of observing $k$ liquefied sites and $n-k$ nonliquefied sites [Eq. (11)], where $\times$ is the model variables $\left(V_{s 1}, \mathrm{CSR}\right.$, $M_{w}$, etc. $), \Theta$ are the model parameters, and $\widehat{g}(\times, \Theta)$ is the limit state model

$$
\begin{aligned}
L(\times, \Theta, \varepsilon) \propto P\{ & \bigcap_{i=1}^{k}\left[\widehat{g}\left(\times_{i}, \Theta_{i}\right)+\varepsilon_{i} \leq 0\right] \\
& \left.\times \bigcap_{i=k+1}^{n}\left[\widehat{g}\left(\times_{i}, \Theta_{i}\right)+\varepsilon_{i}>0\right]\right\}
\end{aligned}
$$

Combining the uncertainties from the variables and model error term into a cumulative error term, $\sigma_{\varepsilon}$, the likelihood function can be written in the form of Eq. (12)

$$
\begin{aligned}
L\left(\times, \Theta, \sigma_{\Sigma}\right) \propto & \prod_{i=1}^{k} \Phi\left[-\frac{\widehat{g}\left(\times_{i}, \Theta\right)}{\sigma_{\Sigma i}}\right]^{w, \text { liquefied }} \\
& \cdot \prod_{i=k+1}^{n} \Phi\left[\frac{\widehat{g}\left(\times_{i}, \Theta\right)}{\sigma_{\Sigma i}}\right]^{w, \text { nonliquefied }}
\end{aligned}
$$

where $\Phi=$ standard normal cumulative distribution function.

The global data set of observed liquefaction field performance is dominated by positive liquefaction observations, with a minority of tested sites having not liquefied (Fig. 4). This disproportionate sampling results in a bias that directly impacts the statistical analysis and can produce a skewed prediction, if unchecked. Cetin et al. (2004) investigated this type of bias and produced a methodology to account for what is called choice-based sampling bias, developing a weighting factor $\left(w ; w_{\text {liquefied }} / w_{\text {nonliquefied }}\right)$ to be applied to the likelihood function of Eq. (11). Based on the work of Cetin et al. (2004) and Moss et al. (2006), and consensus of the coauthors of this study, a nonliquefied point weighting factor of 1.5 was used in this study.

Liquefaction probabilities are estimated through a summation of the probabilities of all possible combinations of parameters that will define the limit equation, integrated over the liquefaction domain where the limit state parameter $g$ in Eq. (9) is less than or equal to zero (Moss et al. 2006). Liquefaction probabilities are generated by a mean-value first-order second-moment (MVFOSM) approximation method, and assessed for quality using more accurate first- and second-order reliability methods (FORM and SORM) and Monte 
Carlo simulations as implemented in the program CALREL (Liu et al. 1989).

\section{Shear-Wave Velocity Liquefaction Assessment Procedure}

The global data set is processed to assess the mean and standard deviation of the parameters used to compute seismic demand (CSR) and soil capacity $\left(V_{s 1}\right)$. Bayesian updating solved for the optimum limit state function model parameters $\Theta_{1}-\Theta_{6}$, which minimized the model error term, $\varepsilon$, and the cross correlation of the independent variables. The model solution is presented in Eq. (13).

A twofold procedure is used to compute the final form of the governing equation. Lack of FC data at many colocated borehole,
SPT, and CPT sites required that the limit state model first be evaluated with the FC coefficient fixed at zero. The model coefficients were determined for $V_{s 1}, \mathrm{CSR}, M_{W}$, and $\sigma_{v o}^{\prime}$ from the entire data set as presented in Table S1. In the second follow-up analysis, these coefficients were fixed, and the model coefficient for FC was determined, which produced the lowest model error for the portion of the data set with FC data.

The cumulative normal distribution, $\Phi$ for Eq. (13) is used to develop the probability models for liquefaction based on the $V_{s 1}$ [NORMDIST $\left(\mathrm{P}_{\mathrm{L}}, 0,1, \mathrm{TRUE}\right)$ function in Microsoft Excel; pnorm(argument,0,1) in $R$ (R Core Team 2012); and normcdf (argument,0,1) in MATLAB], and is used to calculate the probability of liquefaction $\left(P_{L}\right)$ and the cyclic resistance ratio (CRR)

$$
P_{L}=\Phi\left\{-\frac{\left[\left(0.0073 \cdot V_{s 1}\right)^{2.8011}-1.946 \cdot \ln (\mathrm{CSR})-2.6168 \cdot \ln \left(M_{w}\right)-0.0099 \cdot \ln \left(\sigma_{v o}^{\prime}\right)+0.0028 \cdot(\mathrm{FC})\right]}{0.4809}\right\}
$$

and

$$
\mathrm{CRR}=\exp \left\{\frac{\left[\left(0.0073 \cdot V_{s 1}\right)^{2.8011}-2.6168 \cdot \ln \left(M_{w}\right)-0.0099 \cdot \ln \left(\sigma_{v o}^{\prime}\right)+0.0028 \cdot \mathrm{FC}-0.4809 \cdot \Phi^{-1}\left(P_{L}\right)\right]}{1.946}\right\}
$$

Contours of probability of liquefaction for the new correlation are plotted in Fig. 4, where the $V_{s 1}$ is plotted against the equivalent uniform $\mathrm{CSR}^{*}$ for $M_{w}=7.5$, and where a duration weighting factor (DWF) is applied to the effective stress normalized event CSR. The adjustment of CSR to CSR ${ }^{*}$ is done by scaling the computed CSR to

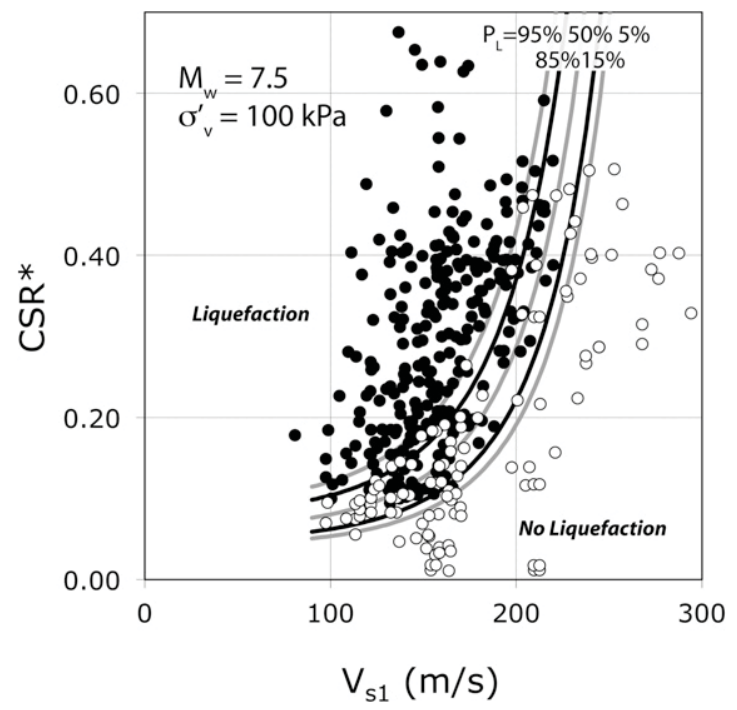

Fig. 4. Plot showing means of field case histories of liquefaction (solid circles) and nonliquefaction (open circles) and new probabilistic correlation curves; the recommended deterministic curve from this study is a factor of safety $(\mathrm{FS})=1.17$ and corresponds with a $P_{L}=15 \%$; the $P_{L}=50 \%$ corresponds with a FS of $=1.0$ compensate for the longer or shorter duration of shaking relative to an equivalent $M_{w}=7.5$ event (Fig. 5).

$$
\mathrm{CSR}^{*}=\mathrm{CSR}_{M w=7.5, \sigma v_{v o}=1 \mathrm{~atm}}=\mathrm{CSR} /\left(\mathrm{DWF} \cdot K_{\sigma}\right) \text {. }
$$

In a previous study by the authors (Cetin et al. 2004), an analysis of $K_{\sigma}$ was done to assess the effect of high-effective overburden pressures of $\sigma_{v o}^{\prime}>2.0 \mathrm{~atm}$ on liquefaction susceptibility. This study's data set is inappropriate for the evaluation of $K_{\sigma}$ for effective stress $>200 \mathrm{kPa}$, because the mean vertical effective stress of the sites is $60.2 \mathrm{kPa}(0.6 \mathrm{~atm})$, and the entire catalog of liquefaction investigation sites is shallower than $22 \mathrm{~m}$ and $180 \mathrm{kPa}(1.8 \mathrm{~atm})$. Given a 4- $\sigma$ model of $\sigma_{v o}^{\prime}, K_{\sigma}$ models would vary only from 0.95 to

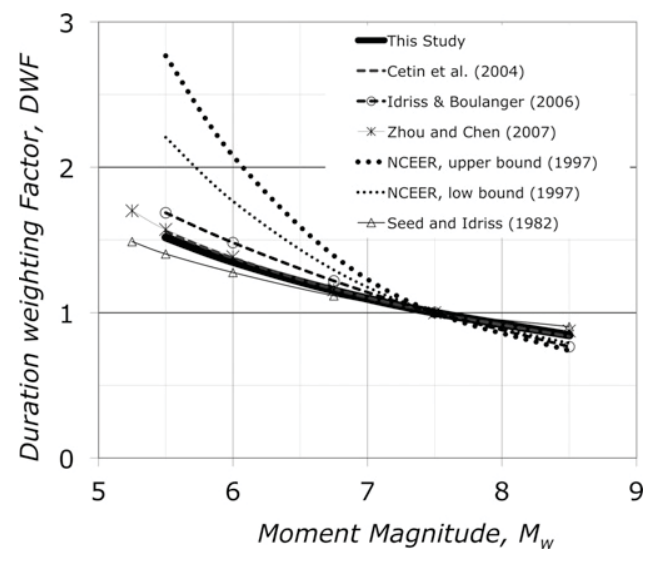

Fig. 5. Comparison of duration weighting factors from this study and previous models 
1.0. As such, the results of this study are presented in terms of CSR ${ }^{*}$ that include $K_{\sigma}$ set to a fixed value of 1.0. The open-and-closed circles in Fig. 4 are the mean values of the probability distributions for $\mathrm{CSR}^{*}$ and $V_{s 1}$ for the individual case histories of the nonliquefaction and liquefaction observations in Table $S 1$, respectively. The curves represent probability of liquefaction $P_{L}$ contours of 5 , $15,50,85$, and $95 \%$.

For the deterministic assessment of liquefaction susceptibility, similar to the intent of models developed in the 1990s (Robertson et al. 1992; Kayen et al. 1992; Lodge 1994; Andrus and Stokoe 2000), the writers recommend the $P_{L}=15 \%$ contour for use as the single deterministic boundary for $V_{s 1}$-based liquefaction evaluation $\left(P_{L}=15 \%\right.$ in Fig. 4). The $P_{L}=15 \%$ contour adheres to the original intent of Seed and Idriss (1971) to have inherent conservatism in the boundary. The deterministic factor of safety against triggering of seismic soil liquefaction is computed as the ratio of the soil capacity to resist liquefaction at $P_{L}(15 \%), \mathrm{CRR}_{, P L(15 \%)}$, and the corresponding seismic demand (CSR)

$$
F S_{\text {liq }}=\frac{\mathrm{CRR}_{P_{L}(15 \%)}}{\mathrm{CSR}}
$$

The factor of safety can be determined either for the given earthquake magnitude and effective overburden stress or from values of CRR and CSR converted to the reference condition of $M_{w}=7.5$, $\sigma_{v o}^{\prime}=1 \mathrm{~atm}$.

\section{Earthquake Duration Weighting Factor}

The data set from this study allows for assessment of the DWF for moment magnitude based on the results of the mean values of the limit state function. In the literature, DWF has also been referred to as magnitude scaling factors (MSF). Evaluation of the effect of $M_{w}$ from Eq. (13) on duration weighting using the parameter mean values results in the following equation:

$$
\mathrm{DWF}=15 M_{w}^{-1.342}
$$

The duration-weighting model from this study that was built from Eq. (13) is plotted in Fig. 5 and is presented with those of previous studies. The model is valid for magnitudes $5.5<M_{w}<9.0$, the range of earthquakes in our data set. The new duration weighting factor from this study is in closest agreement with the models of Cetin et al. (2004) and Zhou and Chen (2007), and falls below Idriss and Boulanger (2008) and the lower boundary proposed by the NCEER Workshop model (Youd et al. 2001). The DWFs in Fig. 6 are recommended for general usage to model magnitude dependent boundary curves ranging between magnitudes 5.5 and 8.5.

\section{Adjustment for the Influence of Fines}

The impact of FC in liquefaction engineering, in general, has three potential avenues for assessment: (1) intergranular soil mechanics, (2) field penetration measurements (SPT, CPT, etc.), and (3) lowstrain measurements using $V_{s}$. As nonplastic FC increases, the void spaces are in-filled, thereby reducing a loose granular soil's capacity for contracting and generating excess pore pressures. This is valid up to a FC of $25-35 \%$, at which point the fines take over the matrix and control the mechanical behavior (Thevanayagam 1998).

With penetration measurements, an increase in nonplastic fines decreases the frictional resistance on the cone or split-spoon. Increased FC also results in increased excess pore pressures because

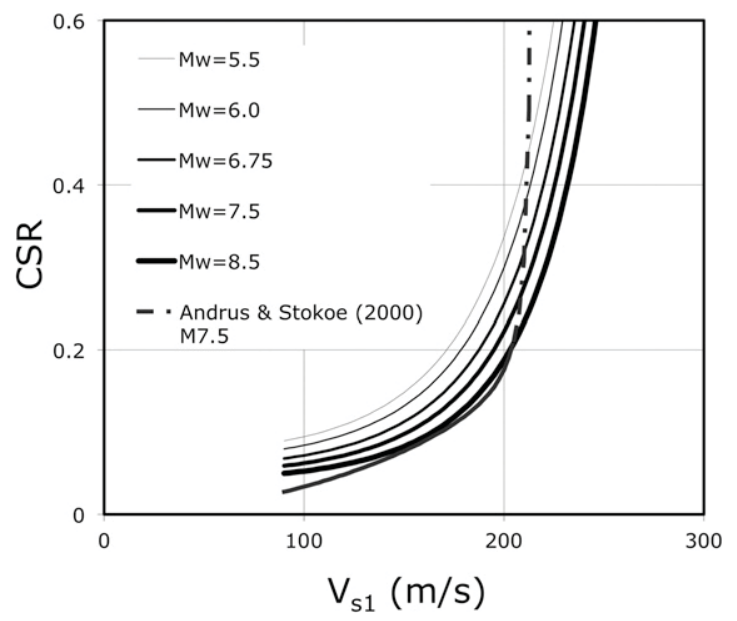

Fig. 6. Correlation curves for magnitudes 5.5-8.5 $\left(P_{L}=15 \%\right.$; $\left.\sigma_{v o}^{\prime}=100 \mathrm{kPa}\right)$

of the lower permeability, and therefore, decreased effective stress on the penetration interface. The response moves toward more of an undrained response compared with the generally drained response for clean sands. This effect is particularly true for cone measurements. Thus, the fines effect on penetration-based liquefaction correlation boundaries is strong (Polito 1999).

The last influence, which is specific to $V_{s}$, is because it is a small strain test. There is little difference between the $G_{\max }$ of sand and silty or clayey sand; these materials, when undergoing strain, all exhibit generally the same initial stiffness (Iwasaki and Tatsuoka 1977). Therefore, $V_{s}$ measurements may have difficulty picking up small differences in FC.

The first two components, reduced friction and excess pore-water pressure, are well represented in penetration-based triggering correlations. With noninvasive $V_{s}$ measurements, the second component is not present, and thus, the test only measures the frictional and modulus components. This renders $V_{s}$ measurements relatively insensitive to FC. The effect of this insensitivity indicates that the uncertainty regarding FC is small with regard to the assessment of liquefaction resistance. From the data set in Table S1, an analysis of a 26\% subset of the sites (109 sites) with FC data allowed for the estimation of the model coefficient for the percentage of FC. The coefficient for the independent variable FC that minimizes model error is 0.0028 , indicating that there is a small positive influence of soil fines on liquefaction resistance (Fig. 7).

The probabilistic boundary curve for $P_{L}=50 \%$ (for $M_{w}=7.5$, $\sigma_{v o}^{\prime}=100 \mathrm{kPa}$ ) is shown in Fig. 7 to illustrate the effect of the correlations regressed coefficient for FC. The boundary shift associated with a fines adjustment from $<5$ to $35 \%$ has a maximum value of $5 \mathrm{~m} / \mathrm{s}$ - an adjustment consistent with previous studies (Andrus and Stokoe 2000; Zhou and Chen 2007). This is a small adjustment in the assessment of liquefaction; therefore, uncertainties associated with fines are fairly minor in comparison with other aspects of the analysis, namely, the estimation of uncertainty associated with $\mathrm{CSR}^{*}$ and $V_{s 1}$.

\section{Comparison with Previous Relationships}

The $15 \%$ probability contour for initial liquefaction from this study is used as the deterministic boundary curve $(F S=1.17)$, and is plotted in Figs. 1 and 8 against deterministic boundaries from the 
previous studies of Robertson et al. (1992), Kayen et al. (1992), Lodge (1994), Andrus and Stokoe (2000), and Zhou and Chen (2007) for clean sand. The previous deterministic curves are plotted with the CSR range of the original published paper. For all CRR levels, the comparison shows the $V_{s}$ boundary zone in the previous relationships of Lodge (1994) and Zhou and Chen (2007) are close and somewhat lower than the proposed relationship. The model of Zhou and Chen (2007) is a departure from the previous $V_{s}$ studies, in that their study characterized the loading conditions at high CSR levels in a controlled laboratory setting. Although the linkage between field shear velocities and laboratory studies is problematic because of the differences in sedimentation history and stress history, laboratory studies can reveal important characteristics about the shape of the liquefaction boundary. Zhou and Chen (2007) found that for CSR ${ }^{*}$ above $0.5-0.6$, liquefaction was induced in noncemented samples with $V_{s 1}$ values as high as $240 \mathrm{~m} / \mathrm{s}$. Before this field study, the field data in the region of

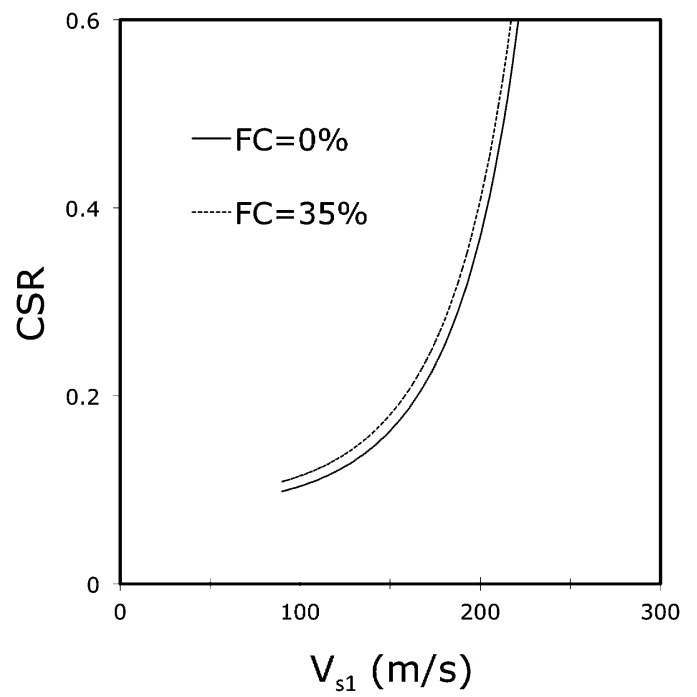

Fig. 7. Adjustment curves for fines content $(\mathrm{FC})=0 \%$ and $35 \%$ fines $\left(P_{L}=50 \%, M_{w}=7.5, \sigma_{v o}^{\prime}=100 \mathrm{kPa}\right)$

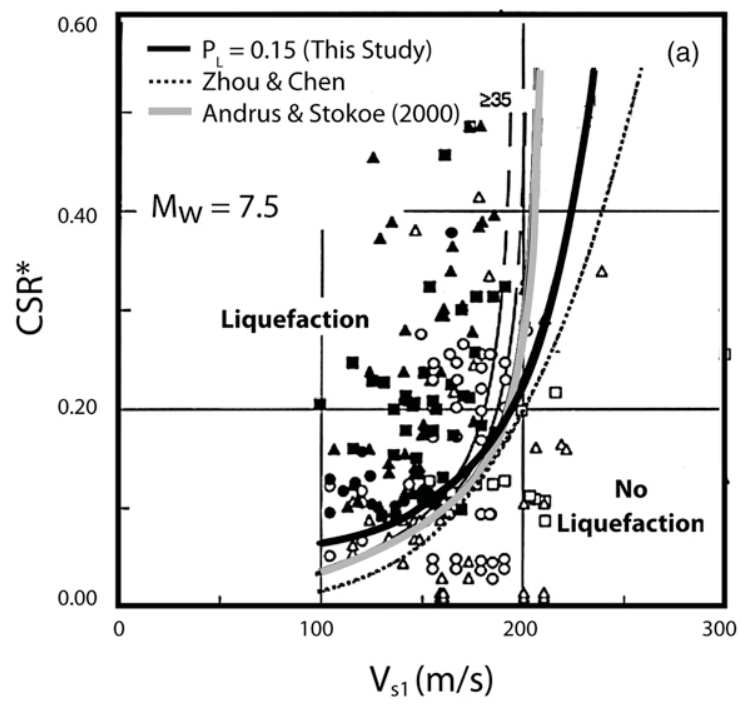

$\mathrm{CSR}^{*}>0.32$ and $V_{s 1}>185 \mathrm{~m} / \mathrm{s}$ was entirely unpopulated for positive-liquefaction sites. The projection of the Andrus and Stokoe (2000) correlation curves above $\mathrm{CSR}^{*}=0.32$ involved extrapolation based on indirect SPT- $V_{s 1}$ relationships. Cataloged moderately stiff soil $\left(V_{s 1}>200 \mathrm{~m} / \mathrm{s}\right)$ liquefaction sites subjected to high $\mathrm{CSR}^{*}$ remain an uncommon event among the global data set of liquefaction performance sites. Among the 422 case histories, only 23 sites fall into this zone.

This study, those of the early 1990s (Robertson et al. 1992; Kayen et al. 1992; Lodge 1994), and the recent study of Zhou and Chen (2007), depart from the limiting upper-bound velocity form proposed by Andrus and Stokoe (2000). The recent proposed lowerbound curve of Zhou and Chen (2007) and the $15 \%$ probability correlation curve proposed here are plotted along with the Andrus and Stokoe (2000) curve for clean sand in Fig. 8. These curves are plotted against the data available in the late 1990s [Fig. 8(a)], and against this study's data set [Fig. 8(b)]. In Fig. 8(a), the Andrus and Stokoe (2000) correlation bounds point to representing liquefaction observations to approximately a CSR level of 0.3. At seismic loading above 0.3 , the boundary was not controlled by liquefaction observations in the data but, rather, indirect SPT- $V_{s}$ relationships. In Fig. 8(a), the proposed boundary curve and that of Zhou and Chen (2007) fall outboard of the Andrus and Stokoe (2000) boundary at CSR levels above 0.2 . In the intervening 10 years, the population of investigated sites has grown nearly an order of magnitude, and in Fig. 8(b), it can be seen that 14 points cross beyond the Andrus and Stokoe (2000) clean sand curve into a frontier previously deemed nonliquefiable. The slope in the boundary curve from this study at high CSR is consistent with the new global data set, as well as the form of the bounding curves for SPT (Cetin et al. 2004) and CPT (Moss et al. 2006). The new global data set and laboratory studies indicate that the concept of a limiting upper bound normalized velocity $V_{s 1}$ of $215 \mathrm{~m} / \mathrm{s}$ for seismic soil liquefaction is unconservative.

An assessment of the probability of liquefaction based on $V_{s}$ was presented by Juang et al. (2002). In Fig. 9, the recommended probabilistic curves from this study are plotted against those of Juang et al. (2002). The principal difference between these studies was the limited data set in 2002. It can be seen that the general shape of the logistic regression analysis of Juang et al. (2002) was not constrained to conform to the limiting upper bound normalized velocity of

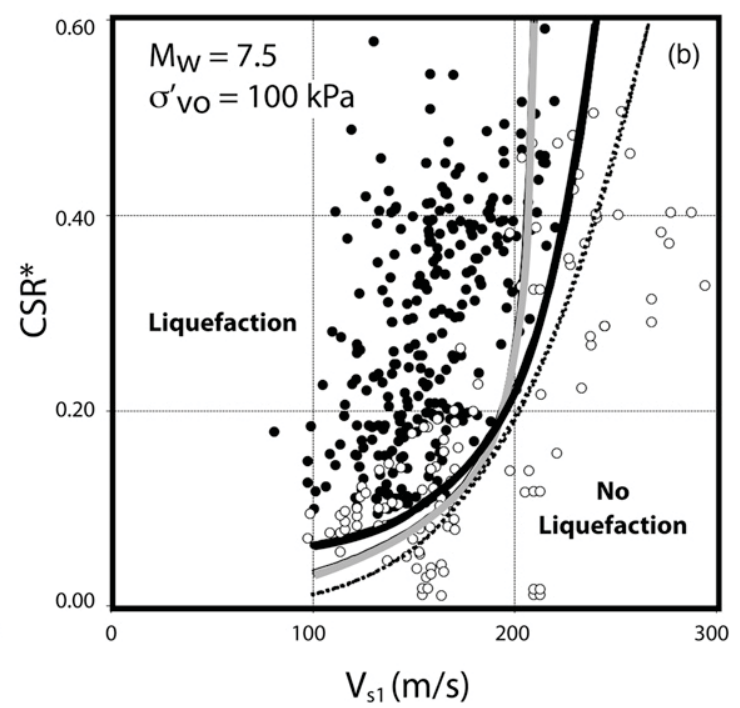

Fig. 8. New data set with recent proposed correlation curves, and those of Andrus and Stokoe (2000): (a) data set of Andrus and Stokoe (2000) and (b) recent proposed correlation curves 


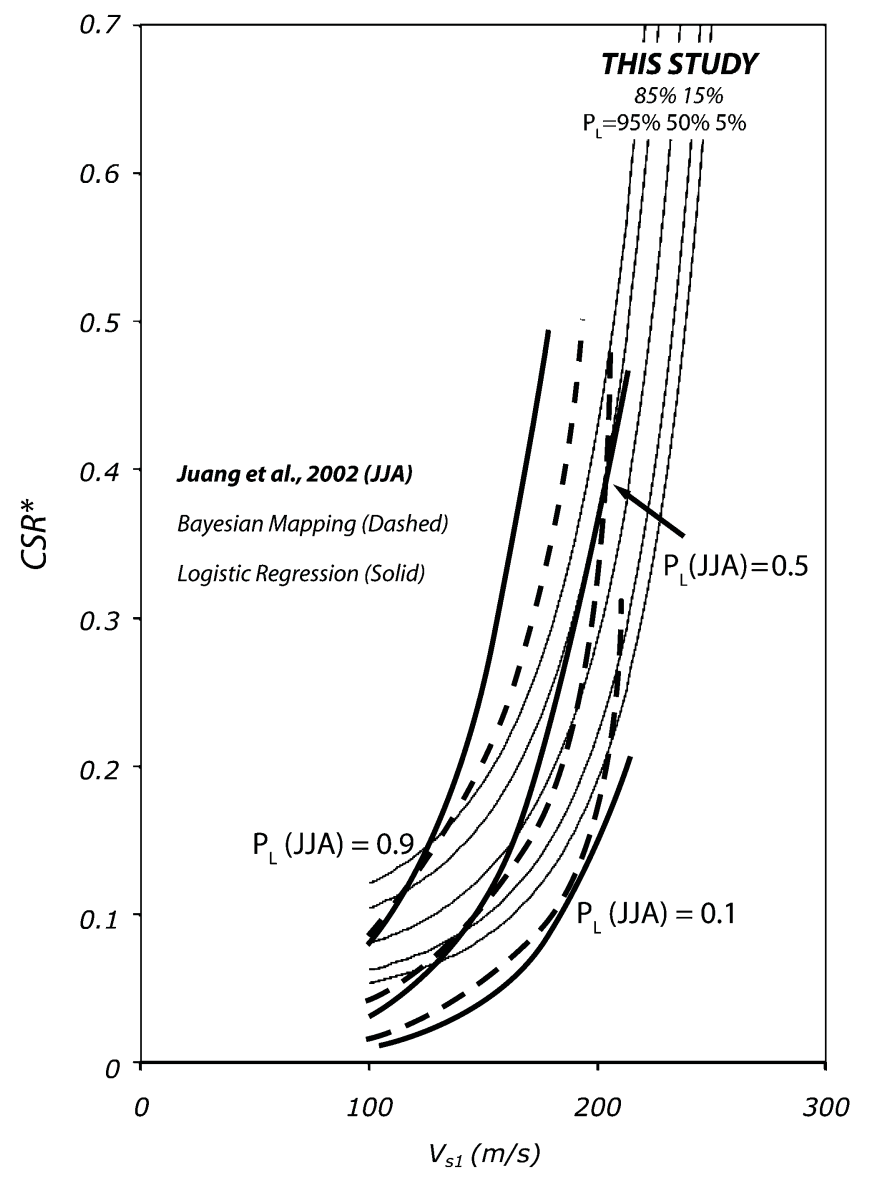

Fig. 9. Comparison of probabilistic curves from this study and those from Juang et al. (2002)

$215 \mathrm{~m} / \mathrm{s}$, and has similar general shape characteristics as the curves in this study. The other characteristic of boundaries presented in this study are their tightening, the result of incorporation of the distributions of the parameters in the multifold integration. The tightening of the probabilistic boundary curves is consistent with the tightening observed in the SPT and CPT analyses of Cetin et al. (2004) and Moss et al. (2006) and is the result of refinements in the handling and processing of the limit-state model parameters and their distributions.

\section{Summary}

This paper presents the development of new generalized correlations for $V_{s 1}$-based evaluation of seismically-induced soil liquefaction. Probabilistic models for initiation of soil liquefaction are developed within a Bayesian model framework and structural reliability models. The probabilistic analysis involves estimation of the uncertainties of the relevant limit state equation variables by characterizing their means and dispersion at each observation site, as well as the estimation of the overall Bayesian model error.

The new correlations rely on the probabilistic foundation provided by the previous studies of the writers for the treatment of $r_{d}$, mean and dispersion of parameters used to compute CSR, and the DWF. A noteworthy product of this study is a new model of DWF that is a direct result of the limit state model solution. The DWF presented here is closest to that proposed by Cetin et al. (2004) and Zhou and Chen (2007).
The new $V_{s 1}$ correlations employ a global database of field performance case histories collected over an 11-year period specifically to overcome the limitations of previous data sets. The guiding locations for collection of this new data set were the comprehensive SPT and CPT catalogs of the previously noted studies, and augmented by scores of independent site investigation reports, as well as better understanding and site access at many locations in China, Taiwan, and Japan. In processing these data and those derived from the literature, screening was done to remove sites where parameter uncertainties were unacceptably large. The new correlations provide significant insight into the assessment of seismic soil liquefaction at high CSR values, specifically, that there is no basis for limiting the upper bound of $V_{s 1}$ at $215 \mathrm{~m} / \mathrm{s}$ for liquefaction sites. The development of generalized $V_{s 1}$-liquefaction correlations requires the cautionary understanding that some soils with unusual soil-specific void ratio-relative density characteristics or bonding may exhibit liquefaction behavior that differs from the generalized proposed relationships. The application of Bayesian analysis and structural reliability methods results in reduced overall model uncertainty compared with previous stochastic analyses.

\section{Acknowledgments}

Financial support was provided through the Unites States Geological Survey (USGS); Pacific Earthquake Engineering Research (PEER) Center's Lifelines Program; EERI-LFE Program; Kobe University, Kobe, Japan; and the Japan Ministry of Education. The writers would like to thank T. Leslie Youd (Brigham Young University); I. M. Idriss (University of California-Davis); Y. Suzuki (Shimizu Corp); H. Taniguchi (Ritsumeikan University, Japan); L. Cluff (PG\&E); Tom Shantz (Caltrans); Diane Minasian (USGS); Brad Carkin (USGS); Ivan Estevez (CCNY); Lena Lai (CCNY); Aliza Zangwill (UCSD); S. Toki (Hokkaido University, Japan); and Albert Hsou (NCHU, Taiwan); and for their insights, assistance, and contributions to the study. X. X. Tao and Lijing Shi (Harbin IT, China) assisted in the collection of the Tangshan area data. Kobe City Parks Department and the City of Nishinomiya provided extensive access to city properties for the Hyogo Nambu earthquake test sites. Brian Collins (USGS), Professor Jon Stewart (University of California-Los Angeles), and three anonymous reviewers are thanked for their critical reviews and insights.

\section{Supplemental Data}

Table S1 is available online in the ASCE Library (www.ascelibrary. org).

\section{References}

Andrus, R. D., and Stokoe, K. H., II. (2000). "Liquefaction resistance of soils from shear-wave velocity." J. Geotech. Geoenviron. Eng., 126(11), 1015-1025.

Andrus, R. D., Stokoe, K. H., II, Riley, M. C., and Bay, J. A. (1998). Liquefaction evaluation of densified sand at approach to Pier 1 on Treasure Island, California, using SASW method. National Institute of Standards and Technology, Gaithersburg, MD.

Andrus, R. D., Stokoe, K. H., II, and Roesset, J. M. (1991). Liquefaction of gravelly soil at Pence Ranch during the 1983 Borah Peak, Idaho earthquake. Soil Dynamics and Earthquake Engineering, V. Soil Dynamics and Earthquake Engineering, London.

Arulanandan, K., Douglas, B. J., Qu, Y. Z., Junfei, X., Chengchun, W., and Qizhi, H. (1982). "Evaluation of earthquake induced liquefaction in 
Tientsin during the Tangshan earthquake P.R.C." Proc., U.S.-P.R.C. Bilateral Workshop on Earthquake Engineering (E-3-1)-(E-3-42).

Asten, M. W., and Boore, D. M. (2005a). "Comparison of shear-velocity profiles of unconsolidated sediments near the Coyote Borehole (CCOC) measured with fourteen invasive and non-invasive methods (in seismic surface waves, O'Neill,)." J. Environ. Eng. Geophys., $10(2), 85$.

Asten, M. W., and Boore, D. M., eds. (2005b). "Blind comparisons of shearwave velocities at closely-spaced sites in San Jose, California." Proc., Workshop U.S. Geological Survey Open-File Report 2005-1169.

Bardet, J. P., Oka, F., Sugito, M., and Yashima, A. (1995). The great Hanshin earthquake disaster, preliminary investigation report. Univ. of Southern California, Los Angeles.

Bay, J. A., and Cox, B. R. (2001). "Shear wave velocity profiling and liquefaction assessment of sites shaken by the 1999 Kocaeli, Turkey earthquake." PEER Project Report SA3017-18336, Pacific Earthquake Engineering Research, Berkeley, CA.

Batilas, A. V., Athanasopoulos, G. A., Pelekis, P. C., Vlachakis, V. S., Klimis, N. S., and Mylonakis, G. E. (2010). "Soil liquefaction at the coastal zone of Kato Achaia in the Achaia-Ilia, Greece, earthquake of June 8, 2008." Proc., 6th Hellenic Conf. on Geotechnical and Geoenviromental Engineering, TEE - ЕЕЕЕГM, Volos, 2011 (in Greek).

Bennett, M. J., and Tinsley, J. C. I. (1995). "Geotechnical data from surface and subsurface samples outside of and within liquefaction-related ground failures caused by the October 17, 1989, Loma Prieta earthquake, Santa Cruz and Monterey Counties, California." Open-File Report 95-663, U. S. Dept. of the Interior, U. S. Geological Survey, Menlo Park, CA.

Bierschwale, J. G., and Stokoe, K. H., II. (1984). "Analytical evaluation of liquefaction potential of sands subjected to the 1981 Westmoreland earthquake." Geotechnical Engineering Report GR 84-15, Univ. of Texas, Austin, TX.

Boore, D. M., and Thompson, E. M. (2007). "On using surface-source downhole-receiver logging to determine seismic slownesses." Soil. Dyn. Earthquake Eng., 27(11), 971-985.

Boulanger, R. W., Idriss, I. M., and Mejia, L. H. (1995). "Investigation and evaluation of liquefaction related ground displacements at Moss Landing during the 1989 Loma Prieta Earthquake." Report No. UCD/CGM-95/ 02, Center for Geotechnical Modeling, Dept. of Civil \& Environmental Engineering, Univ. of California, Davis, CA.

Boulanger, R. W., Mejia, L. H., and Idriss, I. M. (1997). "Liquefaction at Moss Landing during Loma Prieta Earthquake." J. Geotech. Geoenviron. Eng., 123(5), 453-467.

Box, G. E. P., and Tao, G. C. (1992). Bayesian inference in statistical analysis, Wiley, New York.

Brown, L. T., Boore, D. M., and Stokoe, K. H. (2002). "Comparison of shear-wave slowness profiles at 10 strong-motion sites from noninvasive SASW measurements and measurements made in boreholes." Bull. Seismol. Soc. Am., 92(8), 3116-3133.

Cetin, K. O. (2000). "SPT-based probabilistic assessment of the initiation of seismic soil liquefaction." Ph.D. thesis, Univ. of California, Berkeley, CA.

Cetin, K. O., et al. (2000). "Field case histories for SPT-based in situ liquefaction potential evaluation." PEER Report No. UCB/GT-2000/09, Pacific Earthquake Engineering Research, Berkeley, CA.

Cetin, K. O., Seed, R., Der Kiureghian, A., Tokimatsu, K., Harder, L., Kayen, R., and Moss, R. (2004). "SPT-based probabilistic and deterministic assessment of seismic soil liquefaction potential." J. Geotech. Environ. Eng., 130(12), 1314-1340.

Chameau, J. L., Clough, G. W., Reyna, F. A. M., and Frost, J. D. (1991). "Liquefaction response of San Francisco Bayshore fills." Bull. Seismol. Soc. Am., 81(5), 1998-2018.

Chu, D. B., et al. (2004). "Documentation of soil conditions at liquefaction and nonliquefaction sites from 1999 Chi-Chi (Taiwan) earthquake." Soil. Dyn. Earthquake Eng., 24(9-10), 647-657.

Der Kiureghian, A. (1999). "A Bayesian framework for fragility assessment.” Proc., ICASP8 Conf., Sidney, Australia.

Dobry, R., Ladd, R. S., Yokel, F. Y., Chung, R. M., and Powell, D. (1982). Prediction of pore water pressure buildup and liquefaction of sands during earthquakes by the cyclic strain method, National Bureau of Standards Building Sci. Ser, U.S., 138 Washington, DC.

Dupré, W. R., and Tinsley, J. C., III. (1998). "Evaluation of liquefaction hazard mapping in the Monterey Bay area, California." The Loma Prieta Earthquake of October 17, 1989, Vol. 2." U.S. Geological Survey Professional Paper 1551-B, U.S. Geological Survey, Menlo Park, CA, B273-B285.

Earthquake Engineering Research Institute (EERI) Team. (2003). "Preliminary observations on the Tokachi-Oki, Japan, earthquake of September 26, 2003," EERI Special Earthquake Report December 2003, Earthquake Engineering Research Institute, Oakland, CA.

Ejiri, J., Sawada, S., Goto, Y., and Toki, K. (1996). "Peak ground motion characteristics. Special Issue on geotechnical aspects of the January 17, 1995 Hyogoken-Nambu earthquake," Soils Found., 7-13.

Fujimura, H., and Tsumura, T. (2003). "Hazard map of ground liquefaction due to earthquakes in Tottori Prefecture." Proc., Japan National Conf. on Geotechnical Engineering, Vol. JGS38, 171-172.

Fujita, K., and Maeda, Y. (1984). Geology of the Suma district, Geological Survey of Japan. (in Japanese).

Hamada, M., Isoyama, R., and Wakamatsu, K. (1995). The 1995 HyogokenNambu (Kobe) earthquake: Liquefaction, ground displacement and soil condition in the Hanshin Area, Association for Development of Earthquake Prediction, Tokyo.

Hardin, B. O., and Drnevich, V. P. (1972). "Shear modulus and damping in soils: Measurement and parameter effects." J. Soil Mech. Found. Div., 98(6), 603-624.

Harp, E. L., et al. (2003). "Landslides and liquefaction triggered by the M 7.9 Denali fault earthquake of 3 November 2002." GSA Today, 13(4-10).

Hausler, E. A., and Sitar, N. (2001). "Performance of soil improvement techniques in earthquakes." Fourth Int. Conf. on Recent Advances in Geotechnical Earthquake Engineering and Soil Dynamics, Paper 10.15.

Idriss, I. M., and Boulanger, R. W. (2008). "Soil liquefaction during earthquakes." Monograph MNO-12, Earthquake Engineering Research Institute, Berkeley, CA.

Ishihara, K., and Koga, Y. (1981). "Case studies of liquefaction in the 1964 Niigata earthquake.” Soil Found., 21(3), 35-52.

Iwasaki, T., and Tatsuoka, F. (1977). "Effects of grain size and grading on dynamic shear moduli of sands." Soil Found., 17(3), 19-35.

Juang, C. H., Chen, C. J., and Jiang, T. (2001). "Probabilistic framework for liquefaction potential by shear wave velocity." J. Geotech. Geoenviron. Eng., 127(8), 670-678.

Juang, C. H., Jiang, T., and Andrus, R. D. (2002). "Assessing probabilitybased methods for liquefaction evaluation." J. Geotech. Geoenviron. Eng., 128(7), 580-589.

Kameda, M., and Towhata, I. (2003). "Examination on liquefaction potential assessment in Yonago City and its vicinity." Proc., Japan National Conf. on Geotechnical Engineering, Vol. JGS38, 2003-2004.

Kanamori, H. (1977). "Energy-release in great earthquakes." J. Geophys. Res., 82(20), 2981-2987.

Kayen, R., et al. "Field case histories for shear wave velocity assessment of seismic-soil liquefaction from Japan, China, Taiwan, and the United States." USGS SIR Report.

Kayen, R., et al. (2004b). "Geotechnical reconnaissance of the 2002 M7.9 Denali Fault, Alaska earthquake." Earthq. Spectra, 20(3) 639-667.

Kayen, R., et al. (2007). "Investigation of the M6.6 Niigata-Chuetsu Oki, Japan, earthquake of July 16, 2007." U.S. Geological Survey, Open File Report 2007-1365, U.S. Geological Survey, Menlo Park, CA.

Kayen, R., Tanaka, E. Y., Kishida T., and Sugimoto, S. (2002). "Liquefaction potential of native ground in West Kobe, Japan by the spectral analysis of surface waves (SASW) method." Proc., 8th U.S.-Japan Workshop on Earthquake Resistant Design of Lifeline Facilities and Countermeasures against Liquefaction. Tokyo.

Kayen, R. E. (2008a). "Recent damaging earthquakes in Japan, 2003-2008." Proc. 6th Int. Conf. on Case Histories in Geotechnical Engineering.

Kayen, R. E., Mitchell, J. K., Seed, R. B., and Nishio, S. (1998). "Soil liquefaction in the east bay during the earthquake." Professional Paper 1551-B, U.S. Dept. of Interior, U.S. Geological Survey, Menlo Park, CA.

Kayen, R. E., Mitchell, J. K., Seed, R. B., Lodge, A., Nishio, S., and Coutinho, R. (1992). "Evaluation of SPT-, CPT-, and shear wave-based 
methods for liquefaction potential assessment using Loma Prieta Data." Proc., 4th U.S.-Japan Workshop on Earthquake Resistant Design of Lifeline Facilities and Countermeasures Against Soil Liquefaction, Honolulu, HI NCEER.

Kayen, R. E., Seed, R. B. Moss, Robb E. S., Çetin, K. O., Tokimatsu, K. and Tanaka, Y. (2004a). "Global shear wave velocity database for probabilistic assessment of the initiation of seismic-soil liquefaction." 11 th Int. Conf. on Soil Dynamics \& Earthquake Engineering.

Kayen, R. E., Tao X., Shi L., and Shi H. (2008b). "Shear wave velocity investigation of soil liquefaction sites from the Tangshan, China M7.8 earthquake of 1976 using active and passive surface wave methods." Proc., 6th Int. Conf. on Case Histories in Geotechnical Engineering.

Kokusho, T., Tanaka, Y., Kudo, K., and Kawai, T. (1995). "Liquefaction case study of volcanic gravel layer during 1993 Hokkaido-Nansei-Oki earthquake," Proc. 3rd Intern. Conf. on Recent Advances on Soil Dynamics and Geotechnical Earthquake Engineering (St. Louis), 235-242.

Kulhawy, F. H., and Trautmann, C. H. (1996)."Estimation of in-situ test variability," Uncertainty in the geologic environment: From theory to practice (GSP 58). C. D. Shackelford, P. P. Nelson. and M. J. S. Roth, eds. ASCE, New York, 269-286.

Liu, A. H., Stewart, J. P., Abrahamson, N. A., Moriwaki, Y. (2001). "Equivalent number of uniform stress cycles for soil liquefaction analysis." J. Geotech. Geoenv. Eng., 127(12), 1017-1026.

Liu, P., Lin, H., and Der Kiureghian, A. (1989). "CALREL user manual." Structural Engineering Mechanics and Materials Report No. UCB/ SEMM-89/18, Univ. of California, Berkeley, CA.

Lodge, A. L. (1994). "Shear wave velocity measurements for subsurface characterization," Ph.D. thesis, Univ. of California, Berkeley, CA.

Margaris, B., et al. (2010). "The 8 June 2008 Mw6.5 Achaia-Elia, Greece earthquake: Source characteristics, ground motions, and ground failure." Earthq. Spectra, 26(2), 399-424.

Microsoft Excel [Computer software]. Redmond, WA, Microsoft.

Mitchell, J. K., et al. (1994). "In situ test results from four Loma Prieta earthquake liquefaction sites: SPT, CPT, DMT, and shear wave velocity." UCB/EERC-94/04, Earthquake Engineering Research Center, College of Engineering, Univ. of California, Berkeley.

Mori, S., and Kadowaki, Y. (2002). "Site investigation on liquefaction during the 2001 Geiyo earthquake." Proc., Japan National Conf. on Geotechnical Engineering, Vol. JGS37, 1957-1958.

Moss, R. E. S., et al. (2008). "Re-investigating liquefaction case histories from the 1976 Tangshan earthquake." 14th World Conf. on Earthquake Engineering, Beijing.

Moss, R. E. S. (2003). "CPT-based probabilistic assessment of seismic soil liquefaction initiation.” Ph.D. thesis. Univ. of California, Berkeley, CA.

Moss, R. E. S. (2007). "Quantifying measurement uncertainty of thirtymeter shear-wave velocity." Bull. Seismol. Soc. Am. 98(3), 1399-1411.

Moss, R. E. S., Kayen, R. E., Tong, L., Liu, S., Cai, G., and Wu, J. (2009). "Reinvestigating liquefaction and nonliquefaction case histories from the 1976 Tangshan earthquake." Pacific Earthquake Engineering Research Center Report 2009/102, Pacific Earthquake Engineering Center, Berkeley, CA.

Moss, R. E. S., Seed, R. B., Kayen, R. E., Stewart, J. P., and Der Kiureghian, A. (2006). "Probabilistic seismic soil liquefaction triggering using the CPT." J. Geotech. Geoenviron. Eng., 132(8), 1032-1051.

Moss, R. E. S., Seed, R. B., Kayen, R. E., Stewart, J. P., and Tokimatsu, K. (2005). "Probabilistic liquefaction triggering based on the cone penetration test." ASCE GeoFrontiers Conf., ASCE.

Moss, R. E. S., Seed, R. B., Kayen, R. E., Stewart, J. P., Youd, T. L., and Tokimatsu, K. (2003). "Field case histories for CPT-based in situ liquefaction potential evaluation." Geoengineering Research Report No. $U C B / G E-2003 / 04$., Univ. of California, Berkeley, CA.

National Center for Research on Earthquake Engineering (NCREE). (1999). "Geotechnical reconnaissance report of the $921 \mathrm{Ji}-\mathrm{Ji}$ earthquake, Taiwan." National Advanced Project in Hazard Mitigation (NAPHM), and Taiwan Geotechnical Society (GST) (in Chinese).

Nazarian, S., and Stokoe, K. H. (1984). "In situ shear wave velocities from spectral analysis of surface waves." Proc., 8th World Conf. on Earthquake Engineering, Vol. III, Prentice-Hall, Englewood Cliffs, NJ, 31-38.
Noboru, S., and Eiji, S. (2002). "Liquefaction during the 2001 Geiyo earthquake Atsunori Numata." Proc., Japan National Conf. on Geotechnical Engineering, Vol. JGS37, 1955-1956.

Nozu, A. (2002). "Influence of ground motion polarity on the damage at Sakai Port during the 2000 Tottori-ken Seibu earthquake." Proc., Japan National Conf. on Geotechnical Engineering, Vol. JGS37, 2137-2138.

Ochiai, E., Kanemaru, T. Xu, T, Yamamoto, H. Tominaga, K., and Nanba, S. (2002). "Analysis for liquefaction in Hiroshima region during the Geiyoearthquake.” Proc., Japan National Conf. on Geotechnical Engineering, Vol. JGS37, 1963-1964.

Office of the Engineer. (1949). "The Fukui Earthquake, Hokuriku Region, Japan, 28 June 1948." General Headquarters, Far East Command.

Oka, F., Sugito, M., Yashima, A., Taguchi, Y., and Sekiguchi, K. (1996). "Analysis of strong motion records from the South Hyogo earthquake of January 17, 1995.” Eng. Geol., 43(2-3), 85-106.

Park, C., Miller, R., and Xia, J. (1999). "Multichannel analysis of surface waves (MASW)." Geophysics, 64(3), 800-808.

Pacific Earthquake Engineering Research (PEER). (2000). "Documentation of soil conditions at liquefaction sites from 1999 Chi-Chi, Taiwan Earthquake.”〈http://www.cee.ucla.edu/faculty/Taiwanwebpage/Main. htm $\rangle$.

Polito, C. P. (1999). "The effect of non-plastic and plastic fines on the liquefaction of sandy soils." Ph.D. thesis. Virginia Polytechnic Institute and State Univ., Blacksburg, VA.

R Core Team (2012). R: A language and environment for statistical computing. R Foundation for Statistical Computing, Vienna, Austria. $\langle$ http://www.R-project.org/〉.

Rix, G. J., and Lai, C. G. (1998). "Simultaneous inversion of surface wave velocity and attenuation" geotechnical site characterization." Proc., 1st Int. Conf. on Site Characterization - ISC '98, P. K. Robertson and P. W. Mayne, eds. Atlanta, 503-508.

Rix, G. J., Lai, C. G., Orozco, M. C., Hebeler, G. L., and Roma, V. (2001). "Recent advances in surface wave methods for geotechnical Site characterization." Proc., XV Int. Conf. on Soil Mechanics and Geotechnical Engineering, A. A. Balkema, Lisse, Netherlands, 499-502.

Robertson, P. K., Woeller, D. J., and Finn, W. D. L. (1992). "Seismic cone penetration test for evaluating liquefaction potential under cyclic loading." Can. Geotech. J., 29(4), 686-695.

Roesset, J. M., Chang, D.-W., and Stokoe, K. H., II. (1991). "Comparison of 2-D and 3-D models for analysis of surface wave tests." Proc., 5th Int. Conf. on Soil Dynamics and Earthquake Engineering, 111-126.

Seed, R. B., et al. (1990). "Preliminary geotechnical aspects of the October 171989 Loma Prieta earthquake." Univ. Cal. Berkeley, Earthquake Engineering Research Center, Report No. UCB/EERC-90/05, Pacific Engineering Research Center, Berkeley, CA.

Seed, R. B., et al. (2003). "Recent advances in soil liquefaction engineering: A unified and consistent framework." Earthquake Engineering Research Center Report No. EERC 2003-06, Pacific Earthquake Engineering Research, Berkeley, CA.

Seed, H. B. and Idriss, I. M. (1971). "Simplified procedure for evaluating soil liquefaction potential.” J. Soil Mech. Found. Div., 97(SM 9), 1249-1273.

Seed, H. B., and Idriss, I. M. (1982). "Ground motion and soil liquefaction during earthquakes." Monograph, Earthquake Engineering Research Institute, Oakland, CA.

Seed, H. B., Idriss, I. M., and Arango, I. (1983). "Evaluation of liquefaction potential using field performance data." J. Geotech. Eng., 109(3), 458482.

Seed, H. B., Tokimatsu, K., Harder, L. F., and Chung, R. M. (1984). "The influence of SPT procedures in soil liquefaction resistance evaluations." Earthquake Engineering Research Center Report No. UCB/EERC-84/ 15, Univ. of California, Berkeley, CA.

Shibata, T., Oka, F., and Ozawa, Y. (1996). "Characteristics of ground deformation due to liquefaction." Soils Found., 65-79.

Stewart, J. P., coordinator. (2001). "Chapter 4: Soil liquefaction. Chi-Chi, Taiwan Earthquake of September 21, 1999 Reconnaissance Report." Earthquake Spectra, 17(Supplement A), 37-60.

Stokoe, K. H. II, Wright, S. G., Bay, J. A., and Roesset, J. M. (1994). "Characterization of geotechnical sites by SASW method," ISSMFE Technical Committee \#10 for XIII ICSMFE, Geophysical Characterization 
of Sites, A. A. Balkema Publishers/Rotterdam \& Brookfield, Netherlands, $15-25$.

Suzuki, M., Tokimatsu, K., Moss, R. E. S., Seed, R. B., and Kayen, R. E. (2003). "CPT-based liquefaction field case histories from the 1995 HyogokenNambu (Kobe) earthquake, Japan.” Geotechnical Engineering Research Report No. UCB/GE-2003/03., Univ. of California, Berkeley, CA.

Tanaka, Y., and Okimura, T. (2001). "In-depth geotechnical data base: Kobe Jibankun for seismic hazard study." Workshop on Archiving and Web Dissemination of Geotechnical Data, Consortium of Organizations for Strong Motion Operating Systems, Pacific Earthquake Engineering Research Center, Berkeley, CA.

Thevanayagam, S. (1998). "Effect of fines and confining stress on steady state strength of silty sands." J. Geotech. Eng., 124(6), 479-491.

Thompson, E. M., Baise, L. G., and Kayen, R. E. (2007). "Spatial correlation of shear-wave velocity in the San Francisco Bay Area sediments." Soil. Dyn. Earthquake Eng., 27(2), 144-152.

Thompson, E. M., Baise, L. G., Kayen, R. E., and Guzina, B. B. (2009). "Impediments to predicting site response: Seismic property estimation and modeling simplifications." Bull. Seismol. Soc. Am., 99(5), 2927-2949.

Tinsley, J. C., and Dupré, W. R. (1992a). "Liquefaction hazard mapping, depositional facies, and lateral spreading ground failure in the Monterey Bay area, central California." Proc., 4th Annual Japan-U.S. Workshop on Earthquake Resistant Design of Lifeline Facilities and Countermeasures for Soil Liquefaction. M. Hamada and T. D. O'Rourke, eds. Honolulu, HI, Vol. 1, 71-86.
Tinsley, J. C., and Dupré, W. R. (1992b). "Geologic aspects of liquefactioninduced ground-failure in the Monterey Bay area, California, during the 10/17/89 Loma Prieta earthquake." Proc., Conf. on Earthquake Engineering Research, Earthquake Engineering Research Institute, San Francisco, CA.

Wang, W. (1979). "Some findings in soil liquefaction," Research Report, Water Conservancy and Hydroelectric Power Scientific Research Institute, Beijing.

Xie, J. (1979). "Empirical criteria of sand liquefaction." Proc., 2nd U.S. National Conf. on Earthquake Engineering, Stanford Univ., Stanford, CA.

Youd, T. L., et al. (2001). "Liquefaction resistance of soils: Summary report from the 1996 NCEER and 1998 NCEER/NSF workshops on evaluation of liquefaction resistance of soils." J. Geotech. Geoenviron. Eng., 12(10), 817-833.

Youd, T. L., Chung, R. M., and Harp, E. L. (1995). "Liquefaction and other geotechnical effects." Hokkaido-Nansei-Oki Earthquake and Tsunami of July 12, 1993 Reconnaissance Report: Earthquake Spectra, EERI, Vol. 11, Sup. A, 49-94.

Zhou, S. G., and Guo, L. J. (1979). Liquefaction investigation in Lutai District, Ministry of Railway, Beijing (in Chinese).

Zhou, S. G., and Zhang, S. M. (1979). Liquefaction investigation in Tangshan District, Ministry of Railway, Beijing (in Chinese).

Zhou, T.-G., and Chen, T.-M. (2007). "Laboratory investigation on assessing liquefaction resistance of sandy soils by shear wave velocity." J. Geotech. Geoenviron. Eng., 133(8), 959-972. 